\title{
Role of parents on screen time of young children in Pokhara metropolitan, Nepal- a cross sectional study
}

\author{
Sharad Koirala (iD, Sanju Banstola, Nirmala Shrestha, Nisha Gurung, \\ Saurabh Kishor Sah, Bimala Sharma* (iD)
}

\author{
Department of Community Medicine, Gandaki Medical College Teaching Hospital and Research Center, Pokhara, Nepal
}

\begin{abstract}
Background: Sedentary lifestyle is a major modifiable risk factor that usually starts from childhood. High screen time is associated with sedentary lifestyle in children; and parents might have played a role in screen time among the children. This study aims to assess the role of parents in the screen time of young children aged five to nine years in Pokhara metropolitan city in Nepal. Methods: A cross sectional study was done among 360 children where respondents were one of the parents of those children. Face to face interview was done using a semi structured questionnaire between March 8 and September 4, 2020. A daily screen time $<2$ hours was taken as a normal value. Descriptive and inferential analyses were done with the data. Chi square test at $5 \%$ level of significance was computed for the inferential analysis. The ethical approval was taken from the Nepal Health Research Council. Results: Of the total 360 children, $54.7 \%$ were male and $35.6 \%$ were aged 9 years. Screen time $>2$ hours was found among $48.6 \%$ children. The screen time of $>2$ hours children was significantly associated with the educational qualification of parents, parental worry and parental permission to watch the screen for tasks like eating, doing homework, not going out or making free time for parents. The screen time of children was not associated with socioeconomic characteristics like parental occupation. Conclusion: Parental characteristics have role in the screen time of children. Parental factors must also be considered while implementing programs to reduce children's screen time.
\end{abstract}

Keywords: parental role, Pokhara, screen time, young children

\section{*Correspondence:}

Dr. Bimala Sharma, Ph.D

Associate Professor, Department of Community Medicine, Gandaki Medical College Teaching Hospital and Research Center, Pokhara, Nepal Email: bimalasharma@gmail.com

Submitted: February 5, 2021

Accepted: May 12, 2021

To cite: Koirala S, Banstola S, Shrestha N, Gurung N, Sah SK, Sharma B. Role of parents on screen time of young children in Pokhara metropolitan, Nepal- a cross sectional study. JGMC Nepal. 2021;14(1):8-13.

DOI: $10.3126 /$ jgmcn.v14i1.34766

\section{INTRODUCTION}

The prevalence of non-communicable diseases (NCDs) is gradually increasing worldwide including Nepal. NCDs are responsible for $71 \%$ of all deaths in the world and $66 \%$ of all deaths in Nepal. ${ }^{1,2}$ People of all age groups are vulnerable to the risk factors contributing to NCDs like physical inactivity and sedentary life style. ${ }^{1}$ Study has shown that physical inactivity and obesity are in increasing trend in Nepal and these risk factors usually start in the childhood or adolescence. ${ }^{2,3}$ Screen time (ST) is the time a child spends in front of an electronic screen like television, computer, tablet, smart phone etc. on a usual school day and week end day. ${ }^{4}$ Average daily screen time should not be more than two hours for children. ${ }^{5}$ The duration a child spends in front of a screen may be affected by different parental factors. A child may learn from the parents or may be exposed to screen due to different situations. Modern households provide access to different electronic gadgets with screen to the family members. The accessibility to such devices has increased the screen time of all the family members including children thereby, increasing the chance of development of NCDs. Different studies have shown that an increase in screen time is associated with low physical activity and obesity. ${ }^{6-8}$ And screen time is increasing among children and adolescents. ${ }^{9-11}$ 
Studies have shown an association between screen time, physical inactivity and obesity in children. ${ }^{8,11,12-15}$ A study in China showed that more screen time in 2 to 18 years children was associated with overweight and obesity. ${ }^{16}$ And another study in China showed that $36.8 \%$ of school aged children had screen time more than 2 hours. ${ }^{17}$

Studies show that screen time of children is affected by socio-demographic, parental and environmental factors. A multinational study conducted among adolescents report that socio-economic status was the most important predictor of screen time. ${ }^{18} \mathrm{~A}$ study in Canada showed the association of increase in weekday screen time of preschool children with eating lunch and dinner in front of the screen and mother being employed. ${ }^{19}$ An association between smaller increase in screen time among toddlers with mother's higher education and lower screen time was seen in a two years follow up study. ${ }^{20} \mathrm{~A}$ study in Australia recommended that family, economic and environmental factors should be addressed in programs to promote child physical activity and reduce sedentary behavior. ${ }^{21}$ A systematic review also suggested that encouragement and support from parents can increase physical activity of children and reduction in parents' own screen time can reduce children's screen time. ${ }^{22}$ A study in Nepal showed that $>69 \%$ of children aged 8 to 12 years watched television $>2$ hours daily and it was associated with obesity. ${ }^{11}$ Different factors including availability of the devices, socio-economic factors, parental and societal factors may influence screen time among young children. This study aimed to assess the role of parents in the screen time of young children aged 5 to 9 years in Pokhara metropolitan city in Nepal.

\section{METHODS}

This study is a part of a study entitled "Prevalence and Correlates of Screen Time, Eating Behavior and Co-occurring of Screen-Time and Unhealthy Eating Behavior among Young Children in Pokhara Metropolitan" which was conducted between February and October 2020. A cross-sectional study was conducted among school going young children aged five to nine years in Pokhara metropolitan city of Nepal. The sample size was calculated using the formula given by Naing et $a{ }^{23}$ for the prevalence study.

For the calculation, $95 \%$ confidence interval $(Z)=1.96$; prevalence $(\mathrm{P})=0.70$ (television watching $>2$ hours), ${ }^{11}$ and precision $(\mathrm{d})=0.05)$ was taken. Therefore, calculated sample size was 322 , and it became 354 after adding $10 \%$ non-response rate. More than the total sample size, 360 children were included in the study.

Three wards were randomly selected among the 33 wards of Pokhara Metropolitan. A list of schools running primary classes in each selected ward was separately prepared and one government and one private school were randomly selected from each ward. Students studying in classes 1 to 4 who were in the age group 5 to 9 were proportionately selected from each school. Parents were requested to take part in the study. Interview was done with one of the parents of the selected students using a semi-structured questionnaire. Children aged 5 to 9 years were the study population and one of their parents were respondents in the study. Parents were asked the duration of screen time of their child in hours and minutes in a usual school day and weekend day. ${ }^{9}$ Screen time was defined as the duration spent watching television, and using smart phones. Separate sheets, using an adaptation of the Adolescent Sedentary Activity Questionnaire (ASAQ) and other studies were used to record the screen time., ${ }^{9,24}$ The screen time of children was classified to high ( $>2$ hours) based on guidelines of $<2$ hours daily screen time as standard. ${ }^{5}$ The independent variables in the study were the age, sex, ethnicity, religion, education and occupation of parents, availability of personal gadgets to children, offering screen time to make children eat, to do homework, to keep them inside home and to have some free time for oneself.

The data entry, cleaning and analysis was done using the statistical package for social sciences (SPSS) version 20.The data was computed for descriptive and bivariate analysis; $5 \%$ level of significance was taken for the inferential analysis. Association of different parental factors with the screen time of children was computed with Chi square. For the validity and reliability of the study, extensive literature review was done, tools and scales used in previous studies were used for data collection, the enumerators were adequately trained and the process of sample selection, data collection and analysis were closely monitored. The prepared semi-structured questionnaire was translated into Nepali language and pretested in similar population following which necessary modifications were made. The ethical approval was taken from the Nepal Health Research Council (NHRC). Before each interview, informed written consent was taken from the parents after describing the objective of the study and ensuring the confidentiality and autonomy.

\section{RESULTS}

Among the surveyed children, more than half (54.7\%) 
were males; $35.6 \%$ were aged 9 years followed by $22.8 \%$ aged 8 years; $31.4 \%$ were students of grade one followed by $25 \%$ of grade two; and more than $64 \%$ of students were from private schools. About $12 \%$ children had their own personal gadgets. Most of the respondents (80\%) were females, i.e., mothers of the children. More than half i.e. $53.9 \%$ of the respondents were at the age of 30-39 years. Nearly half, $45.3 \%$ of respondents belonged to Brahmin/ Chhetri community followed by about 25\% from lower caste and 20\% from Gurung/Magar/Newar community. More than $42 \%$ of respondents were housewives while $20 \%$ had their own business. Nine out of ten respondents were illiterate (Table 1).

Table 1: Characteristics of the study population and respondents $(n=360)$

\begin{tabular}{|c|c|c|}
\hline Characteristics & Number & Percentage \\
\hline \multicolumn{3}{|l|}{ Sex of child } \\
\hline Male & 197 & 54.7 \\
\hline Female & 163 & 45.3 \\
\hline \multicolumn{3}{|l|}{ Age of child (in years) } \\
\hline 5 & 23 & 6.4 \\
\hline 6 & 62 & 17.2 \\
\hline 7 & 65 & 18.1 \\
\hline 8 & 82 & 22.8 \\
\hline 9 & 128 & 35.6 \\
\hline \multicolumn{3}{|l|}{ Grade } \\
\hline One & 113 & 31.4 \\
\hline Two & 90 & 25.0 \\
\hline Three & 81 & 22.5 \\
\hline Four & 76 & 21.1 \\
\hline \multicolumn{3}{|l|}{ Type of school } \\
\hline Public & 127 & 35.3 \\
\hline Private & 233 & 64.7 \\
\hline \multicolumn{3}{|l|}{ Availability of personal gadget } \\
\hline Yes & 43 & 11.9 \\
\hline No & 317 & 88.1 \\
\hline \multicolumn{3}{|l|}{ Sex of respondent } \\
\hline Male & 74 & 20.6 \\
\hline Female & 286 & 79.4 \\
\hline \multicolumn{3}{|l|}{ Age of respondent (in years) } \\
\hline $20-29$ & 120 & 33.3 \\
\hline $30-39$ & 194 & 53.9 \\
\hline$\geq 40$ & 46 & 12.8 \\
\hline \multicolumn{3}{|l|}{ Religion } \\
\hline Hindu & 311 & 86.4 \\
\hline Buddhist and other & 49 & 13.6 \\
\hline \multicolumn{3}{|l|}{ Ethnicity } \\
\hline Brahmin/Chhetri & 163 & 45.3 \\
\hline Gurung/Magar/Newar & 72 & 20.0 \\
\hline Lower caste & 88 & 24.4 \\
\hline Others & 37 & 10.3 \\
\hline \multicolumn{3}{|c|}{ Educational level of respondent } \\
\hline Illiterate & 34 & 9.4 \\
\hline Basic (uptograde8) & 148 & 41.1 \\
\hline Secondary (grade 9 to 12 ) & 146 & 40.6 \\
\hline Higher (bachelor and above) & 32 & 8.9 \\
\hline \multicolumn{3}{|l|}{ Occupation } \\
\hline Housewife & 153 & 42.5 \\
\hline Agriculture & 63 & 17.5 \\
\hline Own Business & 74 & 20.6 \\
\hline Service & 35 & 9.7 \\
\hline Other & 35 & 9.7 \\
\hline
\end{tabular}

Regarding parental perception and permission on the use of electronic gadgets by children, about half of the respondents (48.1\%) never worried about their children's behavior of using gadgets followed by $33.1 \%$ worried sometimes, $12.2 \%$ most of the times and $6.7 \%$ were always worried. About 59\% respondents never offered gadgets to their children to make them not to go out, while $5 \%$ always offered gadgets. Majority of the parents did not offer gadgets to their children to make them eat or make them do homework. About 2\% parents always offered gadgets to their children to make free time for themselves. Of total children, $>2$ hours screen time was found among 48.6\% children (Table 2).

Table 2: Parental perception and permission regarding use of gadgets by children

\begin{tabular}{lcc}
\hline \multicolumn{1}{c}{ Characteristics } & Number & Percentage \\
Worried about children's behavior of using gadgets & & \\
Never & 173 & 48.1 \\
Sometimes & 119 & 33.1 \\
Most of the time & 44 & 12.2 \\
Always & 24 & 6.7 \\
Offering children gadgets to make them not go out & & \\
Never & 212 & 58.9 \\
Sometimes & 97 & 26.9 \\
Most of the time & 33 & 9.2 \\
Always & 18 & 5.0 \\
Offering children gadgets to make them eat & & \\
Never & 303 & 84.2 \\
Sometimes & 33 & 9.2 \\
Most of the time & 12 & 3.3 \\
Always & 12 & 3.3 \\
Offering children gadgets to make them do homework & \\
Never & 334 & 92.8 \\
Sometimes & 19 & 5.3 \\
Most of the time & 6.3 & 1.7 \\
Always & 185 & 51.4 \\
Offering children gadgets to make time for oneself & & 48.6 \\
Never & 267 & 74.2 \\
Sometimes & 72 & $2 \pm 0.0$ \\
Most of the time & 14 & 3.9 \\
Always & 7 & 1.9 \\
Duration of screen time & & \\
2 hours & & \\
\hline & & \\
\hline
\end{tabular}

Table 3 shows the association of total screen time and different independent variables. Among the socio-demographic characteristics of parents, education of parents, availability of personal gadget and screen time of children were statistically significant while, the occupation of parents was not significantly associated with the screen time of children. Regarding the parental perception and permission of the children's screen time, there was statistically significant association between children's screen time and 
parental worry. Similarly, the screen time of children was significantly associated with parental offerings of gadgets for not going out, making the children eat, doing homework and having free time for themselves.

Table 3: Association between total screen time and different variables

\begin{tabular}{|c|c|c|c|c|}
\hline \multirow[t]{2}{*}{ Variables } & \multicolumn{2}{|c|}{ Screen Time } & \multirow[t]{2}{*}{$\begin{array}{l}\text { Chi square/ } \\
\text { T-test value }\end{array}$} & \multirow[t]{2}{*}{$P$ value } \\
\hline & $\begin{array}{c}\leq 2 \text { hours, } n \\
(\%)\end{array}$ & $\begin{array}{c}>2 \text { hours, } n \\
(\%)\end{array}$ & & \\
\hline \multicolumn{5}{|c|}{ Availability of personal gadget } \\
\hline Yes & $10(23.3)$ & 33 (76.7) & \multirow{2}{*}{15.472} & \multirow{2}{*}{$<0.001$} \\
\hline No & $175(55.2)$ & $142(44.8)$ & & \\
\hline \multicolumn{5}{|c|}{ Education level of parents } \\
\hline Illiterate & $21(61.8)$ & $13(38.2)$ & \multirow{4}{*}{8.846} & \multirow{4}{*}{0.031} \\
\hline Basic (up to 8) & $86(58.1)$ & $62(41.9)$ & & \\
\hline Secondary ( 9 to 12 ) & $66(45.2)$ & $80(54.8)$ & & \\
\hline Higher and above & $12(37.5)$ & $20(62.5)$ & & \\
\hline \multicolumn{5}{|l|}{ Occupation (missing 8) } \\
\hline Housewife & $20(55.6)$ & $16(44.4)$ & & \\
\hline Farmer & $15(41.7)$ & $21(58.3)$ & & \\
\hline Own Business & $37(55.2)$ & $30(44.8)$ & & \\
\hline Service & $14(43.8)$ & $18(56.3)$ & & \\
\hline Foreign employment & $44(48.9)$ & $46(51.1)$ & \multirow{3}{*}{5.005} & \multirow{3}{*}{0.543} \\
\hline Construction workers & $22(62.9)$ & $13(37.1)$ & & \\
\hline Other & $27(48.2)$ & $29(51.8)$ & & \\
\hline \multicolumn{5}{|c|}{ Being worried about gadgets use by children } \\
\hline Never & 131 (75.7) & $42(24.3)$ & \multirow[b]{2}{*}{78.94} & \multirow[b]{2}{*}{$<0.001$} \\
\hline $\begin{array}{l}\text { Sometime/most of the } \\
\text { time/always }\end{array}$ & $54(28.9)$ & $133(71.1)$ & & \\
\hline \multicolumn{5}{|c|}{ Offering gadget for making child not going out } \\
\hline Never & $134(63.2)$ & $78(36.8)$ & & \\
\hline $\begin{array}{l}\text { Sometime/most of the } \\
\text { time/always }\end{array}$ & $51(34.5)$ & $97(65.5)$ & 28.834 & $<0.001$ \\
\hline \multicolumn{5}{|c|}{ Offering gadgets for making child to eat } \\
\hline Never & $174(57.4)$ & $129(42.6)$ & \multirow[b]{2}{*}{27.918} & \multirow[b]{2}{*}{$<0.001$} \\
\hline $\begin{array}{l}\text { Sometime/most of the } \\
\text { time/always }\end{array}$ & $11(19.3)$ & $46(80.7)$ & & \\
\hline \multicolumn{5}{|c|}{ Offering gadgets for making child to do homework } \\
\hline Never & $180(53.9)$ & $154(46.1)$ & . & \\
\hline $\begin{array}{l}\text { Sometime/most of the } \\
\text { time/always }\end{array}$ & $5(19.2)$ & $21(80.8)$ & 11.601 & 0.001 \\
\hline \multicolumn{5}{|c|}{ Offering gadget for having free time } \\
\hline Never & $163(61.0)$ & $104(39.0)$ & & \\
\hline $\begin{array}{l}\text { Sometime/most of the } \\
\text { time/always }\end{array}$ & $22(23.7)$ & $71(76.3)$ & 38.607 & $<0.001$ \\
\hline
\end{tabular}

\section{DISCUSSION}

The study explores the role of parents in the screen time of young children in Pokhara Metropolitan city. Screen time $>2$ hours per day was $48.6 \%$ among children aged 5 to 9 years. Other studies also showed high proportion of screen time $>2$ hours; a study in Nepal among children aged 8 to 12 years showed $69.6 \%$ prevalence of screen time $>2$ hours per day. ${ }^{11}$ Similarly a study conducted in China showed the prevalence of screen time $>2$ hours to be $36.8 \%$ among schoolchildren. ${ }^{25}$
Among the socio-demographic characteristics of parents, the educational status of the parents was seen to be significantly associated with the screen time of children which was similar to the findings of a 2 years follow up study in toddlers where a small increase in screen time was associated with mother's higher education. ${ }^{20}$

Access to device can be an important factor for long screen time. The study found there was a significant association between screen time $>2$ hours and having their own gadgets with the children. Regarding the parental perception of children's screen time, a significant association was seen between children's screen time and parental worry. Children of parents who worried much about the screen time were seen to have screen time higher than 2 hours. This could be taken as a sign that parents were becoming conscious about the hazards of higher screen time. Similarly the study has shown that children of parents who permitted watching screen for one or another reason had higher screen time. Screen time of $>2$ hours daily was significantly associated with parental behavior of offering screen time to children for not going out. This may be signifying the scarcity of safe provisions to allow the children to go out for games and recreation in Pokhara. Higher screen time among children was also significantly associated with parental behaviors of offering screen time to make the children eat or do homework. This could mean that parents are also searching for easier ways to motivate children for their routine works. Higher screen time among children was also significantly associated with parental offering of screen to children to make time for themselves. This could be a result of present demanding time and situation where parents are also facing stresses in their daily life and resorting to easy means to get some free time. Appropriate literature for the comparison of the statistics regarding the parental perception and permission could not be found.

The results in this study have shown that higher screen time among children is a public health situation in Pokhara and parental behaviors are closely associated with the problem. It is time that concerned authorities take proper actions to raise the awareness among the parents and children about the hazards of higher screen time in children. Everybody should work towards making a safer environment for children outside their homes and planning in urban development must be done such that infrastructures are constructed to promote the outdoor games, recreations and habits of children including their parents.

The screen time of children might have been increased as the study coincided with the COVID-19 pandemic and 
lockdown period. So, the result should be interpreted cautiously.

\section{CONCLUSION}

Screen time $>2$ hours was found high among young children in Pokhara metropolitan city. It also identified that the role of parents might be an important issue in the duration of screen time of children. Parental perception and permission towards children's screen time is significantly associated with screen time more than 2 hours. Therefore, the efforts from parents might play an important role in reducing the screen time of children. The programs directed towards reducing the screen time of children should also consider parents.

\section{Funding}

Financial support was provided by Nepal Health Research Council, Nepal.

\section{Conflict of interest}

Authors declare that they have no conflict of interest.

\section{Acknowledgement}

We would like to express our sincere gratitude towards the Nepal Health Research Council for providing Provincial Research Grant for this research. We are grateful to the enumerators in data collection and participants for providing valuable information.

\section{REFERENCES}

1. World Health Organisation. Non communicable diseases. Fact sheet. Available from: https://www.who.int/newsroom/factsheets/detail/noncommunicable-diseases. [Accessed 14th November, 2019]

2. World Health Organisation. Non communicable diseases country profiles 2018 https://www.who.int/nmh/countries/2018/npl_en.pdf?ua=1. [Accessed 14th November, 2019]

3. Biddle SJ, Pearson N, Ross GM, Braithwaite R. Tracking of sedentary behaviors of young people: a systematic review. Preventive medicine. 2010 Nov 1;51(5):345-51. DOI: 10.1016/j.ypmed.2010.07.018

4. Kabali HK, Irigoyen MM, Nunez-Davis R, Budacki JG, Mohanty $\mathrm{SH}$, Leister $\mathrm{KP}$, et al. Exposure and use of mobile media devices by young children. Pediatrics. 2015 Dec 1;136(6):1044-50. DOI: 10.1542/peds.2015-2151

5. Strasburger VC. Children, adolescents, obesity, and the media. Pediatrics. 2011 Jul;128(1):201-8. DOI: 10.1542/ peds.2011-1066

6. Marsh S, Mhurchu CN, Maddison R. The non-advertising effects of screen-based sedentary activities on acute eating behaviours in children, adolescents, and young adults. A systematic review. Appetite. 2013 Dec 1;71:259-73. DOI: 10.1016/j.appet.2013.08.017

7. Iannotti RJ, Janssen I, Haug E, Kololo H, Annaheim B, Borraccino A. Interrelationships of adolescent physical activity, screen-based sedentary behaviour, and social and psychological health. International journal of public health. 2009 Sep 1;54(2):191-8. DOI: 10.1007/s00038-009-5410-z

8. Fuller-Tyszkiewicz M, Skouteris H, Hardy LL, Halse C. The associations between TV viewing, food intake, and BMI. A prospective analysis of data from the Longitudinal Study of Australian Children. Appetite. 2012 Dec 1;59(3):945-8. DOI: 10.1016/j.appet.2012.09.009

9. Pearson N, Griffiths P, Biddle SJ, Johnston JP, McGeorge S, Haycraft E. Clustering and correlates of screen-time and eating behaviours among young adolescents. BMC Public Health. 2017 Dec;17(1):533.

10. Sharma B, Cosme Chavez R, Jeong A, Nam E. Television viewing and its association with sedentary behaviors, self-rated health and academic performance among secondary school students in Peru. International journal of environmental research and public health. 2017 Apr;14(4):383. DOI: 10.3390/ijerph14040383

11. Chhetri S, Yadav DK. Association of Television Watching on Physical Activity and Obesity among Children in Pokhara Nepal. JHAS. 2019;9(1):1-6. DOI:org/10.37107/jhas.1

12. Janssen I, Katzmarzyk PT, Boyce WF, Vereecken C, Mulvihill C, Roberts C, et al. Health Behavior in School-Aged Children Obesity Working Group. Comparison of overweight and obesity prevalence in school-aged youth from 34 countries 70 and their relationships with physical activity and dietary patterns. Obesity reviews. 2005 May;6(2):123-32. DOI: 10.1111/j.1467-789X.2005.00176.x

13. Jordan $\mathrm{AB}$, Robinson $\mathrm{TN}$. Children, television viewing, and weight status: summary and recommendations from an expert panel meeting. The ANNALS of the American Academy of Political and Social Science. 2008 Jan;615(1):119-32. DOI: 10.1177/0002716207308681

14. Davison KK, Marshall SJ, Birch LL. Cross-sectional and longitudinal associations between TV viewing and girls' body mass index, overweight status, and percentage of body fat. The Journal of pediatrics. 2006 Jul 1;149(1):32-7. DOI: 10.1016/j.jpeds.2006.02.003

15. Karki A, Shrestha A, Subedi N. Prevalence and associated 
factors of childhood overweight/obesity among primary school children in urban Nepal. BMC public health. 2019 Dec 1;19(1):1055. DOI: 10.1186/s12889-019-7406-9

16. Shan XY, Xi B, Cheng H, Hou DQ, Wang Y, Mi J. Prevalence and behavioral risk factors of overweight and obesity among children aged 2-18 in Beijing, China. International journal of pediatric obesity. 2010 Oct;5(5):383-9. DOI: $10.3109 / 17477160903572001$

17. National Planning Commission (NPC). Nepal's Sustainable Development Goals Baseline Report National Planning Commission, Government of Nepal. June 2017.

18. Ngantcha M, Janssen E, Godeau E, Ehlinger V, Le-Nezet O, Beck F, et al. Revisiting factors associated with screen time media use: a structural study among school-aged adolescents. J Phys Act Heal [Internet]. 2018 Jun 1;15(6):448-56. DOI: 10.1123/jpah.2017-0272

19. Birken CS, Maguire J, Mekky M, Manlhiot C, Beck CE, Jacobson $S$, et al. Parental factors associated with screen time in preschool 71 children in primary-care practice: a TARGet Kids! study. Public health nutrition. 2011 Dec;14(12):2134-8. DOI: 10.1017/S1368980011000516

20. Matarma T, Koski P, Löyttyniemi E, Lagström H. The factors associated with toddlers' screen time change in the STEPS
Study: a two-year follow-up. Preventive medicine. 2016 Mar 1;84:27-33. DOI: 10.1016/j.ypmed.2015.12.014

21. Smith BJ, Grunseit A, Hardy LL, King L, Wolfenden L, Milat A. Parental influences on child physical activity and screen viewing time: a population based study. BMC public health. 2010 Dec 1;10(1):593. DOI: 10.1186/1471-2458-10-593

22. Xu H, Wen LM, Rissel C. Associations of parental influences with physical activity and screen time among young children: a systematic review. Journal of obesity. 2015 Jan 1;2015. DOI:org/10.1155/2015/546925

23. Naing L, Winn T, Rusli BN. Practical issues in calculating the sample size for prevalence studies. Archives of orofacial Sciences. 2006; 1:9-14.

24. Hardy LL, Booth ML, Okely AD. The reliability of the adolescent sedentary activity questionnaire (ASAQ). Preventive medicine. 2007 Jul 1;45(1):71-4. DOI: 10.1016/j. ypmed.2007.03.014

25. Cai Y, Zhu X, Wu X. Overweight, obesity, and screen-time viewing among Chinese school aged children: national prevalence estimates from the 2016 Physical Activity and Fitness in China-The Youth Study. Journal of sport and health science. 2017 Dec 1;6(4):404-9. DOI: 10.1016/j.jshs.2017.09.002 